\title{
Selectivity in regeneration of the oculomotor nerve in the cichlid fish, Astronotus ocellatus
}

\author{
by R. W. SPERRY and H.L. ARORA ${ }^{1}$ \\ From the California Institute of Technology
}

IT has long been considered a general rule for nerve regeneration that the reinnervation of skeletal muscle is nonselective. Regenerating nerve fibers are supposed to reconnect with one skeletal muscle as readily as another according to studies covering a wide range of vertebrates (Weiss, 1937; Weiss \& Taylor, 1944; Weiss \& Hoag, 1946; Bernstein \& Guth, 1961; Guth, 1961, 1962, 1963). Similarly, in embryogenesis proper functional connexions between nerve centers and particular muscles are supposedly attained, not by selective nerve outgrowth but rather through a process of 'myotypic modulation' (Weiss, 1955) that presupposes nonselective peripheral innervation.

Doubt about the general validity of this rule and the concepts behind it has come from a series of studies on regeneration of the oculomotor nerve in teleosts, urodeles, and anurans and of spinal fin nerves in teleosts (Sperry, 1946, 1947, 1950, 1965; Sperry \& Deupree, 1956; Arora \& Sperry, 1957a, 1964). All point to the existence of basic selectivities in the formation of nerve-muscle connexions that vary in degree in different systems and in different species.

Some 8 years ago we observed that complete section of the oculomotor nerve in cichlid fishes is soon followed by a full recovery or orderly and normally-patterned eye movements even when the nerve trunk is roughly teased apart with inevitable scrambling of the heterogeneous fibers of this nerve that supplies four of the extrinsic muscles of the eye (Arora \& Sperry, 1957a). The following is an account of these and subsequent experiments that have been carried out in the interim in an effort to determine what kinds of factors are responsible for this extraordinary recovery that was taken initially to be another example of 'myotypic modulation'. The present findings point instead to an explanation in terms of selective peripheral innervation.

\section{MATERIAL AND METHODS}

Young and immature specimens of the cichlid Astronotus ocellatus were used throughout ranging in overall length from 3 to 9 centimeters. This fish was selected initially because the eyes are relatively large and their movement more

${ }^{1}$ Authors' address: Division of Biology, California Institute of Technology, Pasadena, California 91109, U.S.A. 
pronounced and more extensive than in some other freshwater species. The general procedures for maintenance and for anesthesia and surgery have been described elsewhere (Arora \& Sperry, 1957b, 1963). Pertinent details of the surgery for different types of nerve-muscle rearrangement described below are given in context.

Action of the reinnerverted ocular muscles was determined by comparing the eye movements on the operated side with the normal movements on the unoperated or control side. To make the comparisons more direct, various individual muscles and/or their nerves were resected on the control side in a variety of combinations to match the different experimental conditions in the test orbit.

Spontaneous and reflex movements of the eyes were observed while the fish were at rest or in voluntarily maintained positions of tilt within small clear tanks. Closer observations of forced reflex reactions, particularly those elicited by tilting the fish around the three main axes of the body, were obtained by placing the fish in a narrow observation chamber of clear plexiglas. Cotton padding was placed around the trunk and tail until the fish was fairly well immobilized with the eyes and gills left uncovered.

A variety of surgical controls was applied in all phases of the experiments to check against misregeneration effects and vicarious movements produced passively and by the action of non-test muscles.

\section{OBSERVATIONS}

\section{Section of main nerve trunk}

The main trunk of the oculomotor nerve (N. III) was completely sectioned on one side in sixteen animals. In half of these the section was carried out within the orbit close to where the nerve enters from the cranium. The general anatomical relationships are illustrated in Text-fig. 1 . In the remaining eight cases the section was performed within the cranium through a latero-ventral approach that did not disturb the brain, the motor ocular muscles or other orbital structures. The nerve trunk was divided in a deliberately rough manner to disarrange the fiber pattern outgrowth from the central stump. The freshly divided nerve ends were shredded and teased with a pair of fine jewelers forceps and then the two frayed ends were reapposed.

There was a complete paralysis of the oculomotor musculature for at least 5 days after the nerve section. Return of function was first noted on the 6th to 8th day depending upon the location and severity of the operation, and appeared to reach completion around the 12th day. This recovery schedule was further checked in several cases in which section of nerve III was combined with resection of the other two motor ocular nerves IV and VI, the abducent nerve supplying the lateral rectus muscle and the trochlear nerve supplying the superior oblique muscle.

There was no observable abnormality of timing of muscle action in the early 
stages of recovery, the general impression being that of a direct reinstatement of normal coordination that was very weak at the start and gradually became stronger.

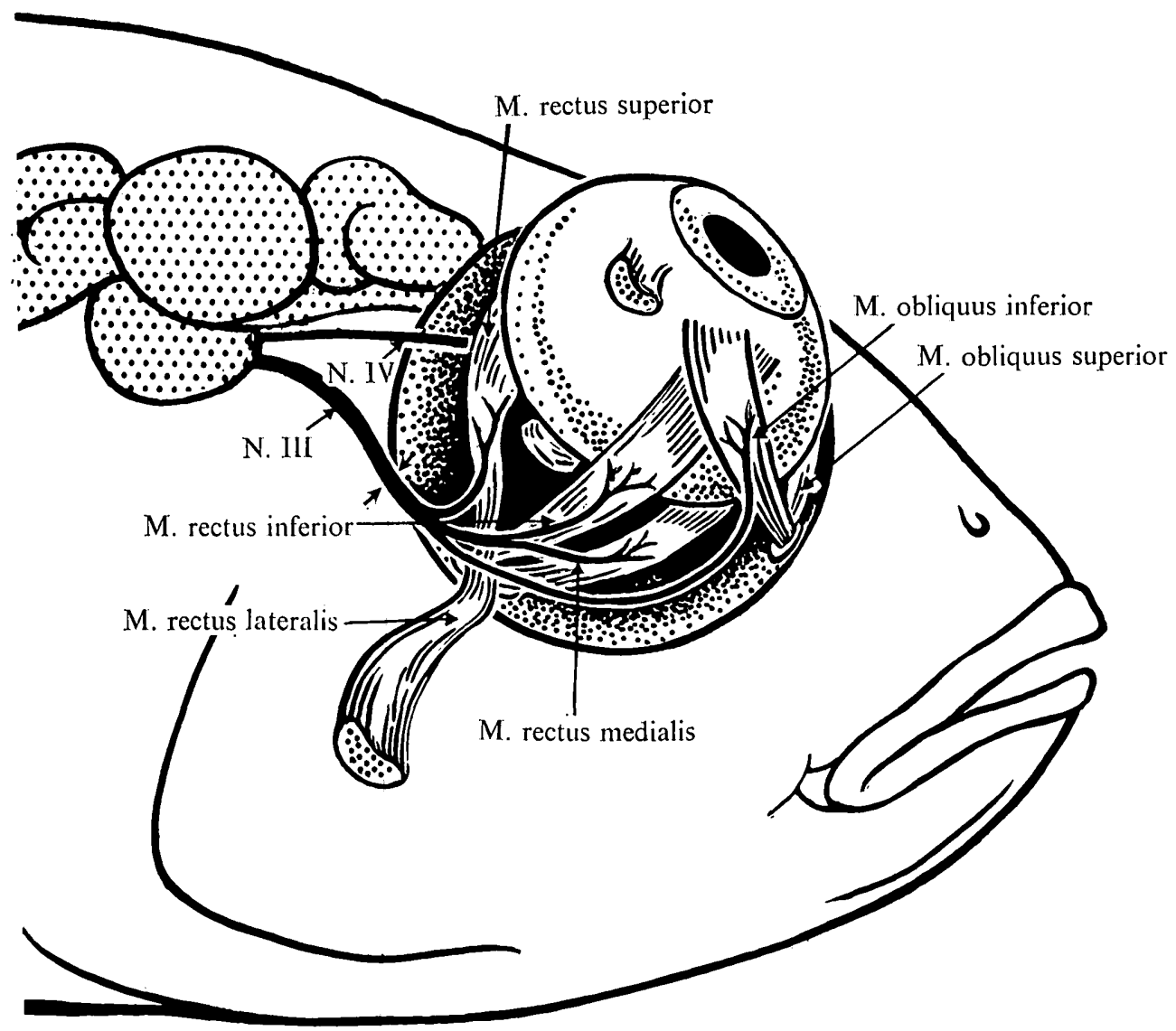

TExT-FIG. 1. Sketch of eye muscles and their innervation in Astronotus ocellatus. The lateral rectus muscle is cut and deflected to expose the branching of the oculomotor (III) nerve. Arrows indicate point of section of N. III.

Two weeks after nerve section the movements of the operated and the normal control eye were indistinguishable in all but three cases. In these three cases the recovered movements appeared to be somewhat less vigorous and extensive than on the normal side. In two of these, excessive bleeding in the orbit at the time of surgery had displaced the incised conjunctiva from its place and the resultant scar tissue hindered the free movement of the eye ball. The other had been an intracranial section and the nerve was found displaced far out of position with apparently a few fibers having made their way to the orbit through the orbital septum. In those cases in which recovery appeared to be complete, one could not rule out the possibility that the strength of the muscle action on the regenerated side might have been somewhat weaker than that on the normal side. With the 
methods used, however, the eye movements on the operated and normal sides were virtually indistinguishable from the third week on.

Excision of muscles still innervated by nerves IV and VI did not disrupt the recovered coordination in the regenerated oculomotor system whereas subsequent resection of the regenerated nerve III itself reinstated complete paralysis. In short, the results of this series fully confirmed our earlier observations in demonstrating an excellent restoration of normally coordinated action in the reinnervated oculomotor musculature.

\section{Electrical tests for multiple muscle innervation}

From earlier studies on restoration of muscle function following disarrangements in nerve-muscle connexions in amphibians it has been concluded that single motor axons by multiple branching in regeneration may come to reinnervate two, three or more different muscles and that such axons are able to activate their separate, nonsynergic muscles independently, each in its proper timing (Weiss, 1928,1936 ). This observation is critical in that it would seem to favor decisively the resonance interpretation over other possible explanations of motor recovery following nerve regeneration.

An attempt was made to test for multiple innervation in the present cases by the same axon reflex method used in the earlier studies. The orbit was opened with the fish anesthetized and the eyeball was removed except for the oculomotor muscle attachments. These were fastened under light tension to a fine hair-like stylus. The terminal portion of the nerve to the inferior oblique muscle was then stimulated locally to see if the other muscles would exhibit any axon reflex contractions. The process was then repeated with the central portion of the oculomotor nerve trunk divided by forceps central to the scar and near the exit from the brain to avoid central reflex transmission. Thorough testing in this manner of four of the fully recovered cases failed to disclose the presence of any definite axon reflex effects.

\section{Surgical interchange of individual muscle nerves}

With re-educative adjustments excluded (Sperry, 1958) the orderly recovery of coordination in the foregoing could be explained by selective regeneration of the four different nerve fiber types back to their original muscles. Or it could be explained in terms of myotypic respecification of those fibers that connected to the wrong muscles following nonselective reinnervation. To distinguish between these two alternative possible explanations more evidence was needed. In the following the nerves of single oculomotor muscles were forcibly connected by direct insertion into a different, i.e. foreign muscle. Selective innervation was thus excluded in these following experiments. Any recovery of proper timing in muscle action would have to be ascribed therefore to myotypic specification of nerve by muscle.

The action of the extrinsic ocular muscles is not simple nor easy to follow in 
these small specimens. Several different combinations of nerve-muscle rearrangements were tried and repeated over a 4-year period in the process of arriving at a definite answer. The normal innervation of the muscles and the various types of nerve crosses that were studied are summarized schematically in Text-fig. 2.

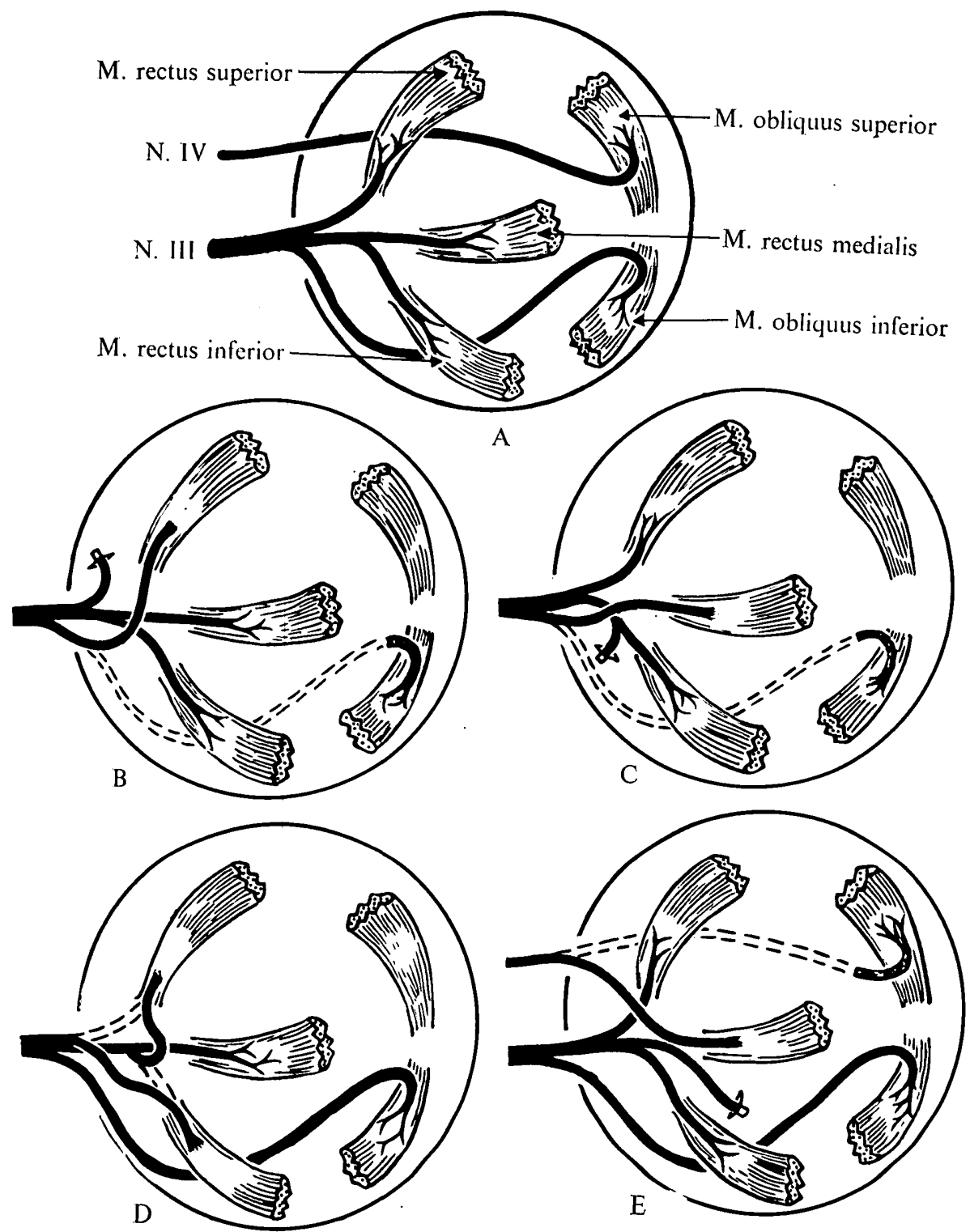

TEXT-FIG. 2. Surgical interchange among motor ocular nerve connexions, schematic: Designation of muscles with normal innervation as indicated in $\mathrm{A}$. The abducens nerve and muscle, not involved in the transplantation, are omitted. B. Inferior oblique nerve crossed into superior rectus muscle; nerve of superior rectus deflected into orbital septum. C. Inferior oblique nerve crossed into medial rectus muscle, nerve of medial rectus deflected into septum. D. Nerves of superior and inferior rectus muscles interchanged. E. Superior oblique nerve cut and crossed into medial rectus muscle, nerve of medial rectus deflected into septum. 
In one series of seven cases the nerve of the inferior oblique muscle was cut and inserted into the freshly denervated superior rectus muscle (Text-fig. 2B). In the second series of ten cases, the same nerve was inserted into the denervated medial rectus muscle (Text-fig. 2C). In another series of eight cases the nerves of the superior and inferior rectus muscles were both cut and cross-connected to the opposing muscle, i.e. the nerves of inferior and superior rectus muscles were interchanged (Text-fig. 2D). In a final series of six cases the trochlear nerve (N. IV) was cut and inserted into the denervated medial rectus muscle (Text-fig. 2E). The original nerve of the host muscle in each case was deflected away as far as possible and inserted into the nearby mandibular muscules in some cases and, in others, into the opposite orbit through the inter-orbital septum.

In all cases, the crossed nerves were able to grow into the foreign muscles and to establish transmissive functional connexions so that the reinnervated muscles contracted both reflexly and to electrical stimulation of the regenerated nerve. However, one got a distinct impression that was difficult to quantify, that the reinnervation by foreign nerves did not proceed so rapidly, so fully, nor with such good functional results as did reinnervation by the original nerve. Further, the original nerve showed a marked tendency to grow back into its own muscle in spite of the factors favoring its invasion into the foreign muscle. Extra measures had to be taken during the surgery to prevent the regrowth of normal connexions, such as excision of the original muscle in some cases and always deflection and insertion of the unwanted nerve into distant tissues.

The fish were tested daily for recovery of muscle function during the first 2 weeks after the original operation and at increasing intervals thereafter through a period of 3 to 4 months. In testing the timing of the reinnervated muscles in reflex activities, the action of the specific muscles and nerves in question was clarified by eliminating the action of non-test muscles and/or their nerves in a variety of different combinations. The findings may be summarized as follows:

Transmissive functional connexions were generally established between the regenerated nerves and the foreign muscles into which they had been inserted. In no instance was there a clear restoration of the normal timing of eye movements. The eye movements were either clearly abnormal or the movement was too weak to interpret. In cases in which the inferior and superior rectus nerve branches had been crossed, there was little or no eye movement in response to tilting, the only observable reaction being a slight trembling of the eyeball. In other cases in which the inferior oblique or the trochlear nerve had been forced to grow into a denervated foreign muscle, the reinnervated muscle responded atypically to produce abnormal reflex movements of the eyeball of a type that indicated retention of the original timing of the regenerated nerve. In no case was it convincingly apparent that the transposed nerve had given up its original timing and taken on a new pattern of discharge to suit the new muscle. In general the weak abnormal responses obtained in this series contrasted markedly with the excellent strong recoveries obtained in the preceding series and in the several control cases 
of the present series, in which the original nerve was cut and reimplanted into its own muscle and the non-test muscle action eliminated by de-nervating the muscles.

\section{Competitive reinnervation}

Some additional cases were prepared in an effort to obtain further evidence regarding the presence of possible factors that might favor the formation of normal over abnormal nerve-muscle connexions. In eight fish the severed superior rectus muscle nerve was reinserted into its own muscle simultaneously with a foreign nerve from the inferior oblique muscle. In another series of seven fish, the medial rectus nerve was cut and reinserted in its own muscle along with the foreign nerve from the inferior oblique muscle. Every effort was made in carrying out the surgery to give both the original and the foreign nerves an equal chance to establish functional connexions as far as positional and mechanical factors were concerned. When tested by tilt reflexes 12 days after the operation the recovered function of the original nerves was strongly dominant in all cases. No influence of the foreign nerve on the test muscle was detectable even after 20 to 30 days after the operation. In 3 cases in the latter series the whole of the inferior oblique nerve or at least the main part of it had grown through the foreign medial rectus muscle without leaving connexions and had then made its way along the nearby connective tissue until it reached its own muscle which it had innervated with repeated branching in typical manner.

Another series of ten fish were similarly operated except that the regrowth of the original nerve was delayed by crushing it far proximally near the junction of the main trunk. This crushing of the original nerve was then repeated in a second operation 5 days later until functional testing showed that reinnervation by the foreign nerve had been established. The original nerve was then allowed to regenerate into the muscle. Under these conditions the original nerve again gradually acquired dominant control of the muscle and contractions via the foreign nerve were no longer demonstrable after 2 weeks. This ability of the original nerve to recapture its own muscle after that muscle had already become well innervated by a foreign nerve appears to be at variance with findings obtained in mammals (Guth, 1962, 1963). This difference may be correlated with the presence of the multiterminal type of neuromyal synapse found in teleosts (Mark, 1965).

\section{DISCUSSION}

The orderly recovery of normal eye movements following complete section and regeneration of the main oculomotor nerve trunk indicates selective restoration of the coordinate activation of the four muscles involved. This excellent recovery of proper function stands in marked contrast to the persistent squint, contracture, and undifferentiated mass action observed to follow regeneration of the divided oculomotor nerve in man and chimpanzee (Bender \& Fulton, 1938; Sperry, 1946; 
Wartenberg, 1946) that presumably is characteristic of mammals in general. The present result is more comparable with the kind of recovery obtained after regeneration of mixed cranial and spinal nerves in fishes and in larval and adult salamanders (Weiss, 1936; Sperry, 1947, 1950, 1958; Sperry \& Deupree, 1956; Arora \& Sperry, 1957).

Functional recoveries of this latter sort have been explained in the past in terms of random, nonselective reestablishment of nerve-muscle connexions followed by myotypic respecification of misregenerated fibers. In the present experiments, however, myotypic respecification effects failed to appear when individual nerve branches were separately inserted into foreign muscles. The transplanted nerves retained their original timing and produced abnormal movements of the eyeball. Taken jointly the foregoing findings suggest an explanation in terms of some kind of selectivity in the peripheral reinnervation process.

Selective regrowth was further indicated in the extra difficulty encountered in trying to force the nerves to reinnervate foreign muscles. There appeared to be a definite tendency for the regenerating nerves to restore the normal nerve-muscle combinations even though the latter were strongly disfavored by the mechanical conditions. Peripheral selectivity was further evident in the typically less-thannormal vigor of contraction obtained from the crossed nerve-muscle combinations when these did become functional.

Selectivity in the peripheral reinnervation may also be inferred indirectly from the absence of plural innervation indicated in the electrical tests. Regenerating fibers characteristically undergo multiple branching at the tips of the parent fiber and this is presumed to be an important factor contributing to the abnormal mass contractions that frequently follow nerve regeneration in mammals. The demonstration that a regenerated motor axon could form excess branches to several nonsynergic muscles and yet activate the different muscles selectively each in its proper 'homologous' timing is what lead initially to the law of myotypic response and the resonance principle of nerve function (Weiss, 1931, 1936). The absence of axon reflexes and mass action in the present experiments is taken to mean that such extra connexions, if formed, probably fail to survive in these animals especially if the original nerve also reaches the given muscle and if another branch of the same axon has contact with its own original muscle.

Finally, in those cases in which both the original and a foreign nerve were inserted into the same muscle, giving each equal mechanical access, we have further direct evidence that the original nerve is selectively favored in the reinnervation process. In general terms we can therefore infer the presence of some kind of preferential chemoaffinity in this oculomotor system that favors restoration of the original over foreign nerve-muscle connexions.

On the basis of more recent studies of muscle reinnervation in adult salamander limbs and fish fins, Mark (1965) is now suggesting that the orderly recovery of muscle coordination in the lower vertebrates in general, including the phenomenon of myotypic response, may well be correlated primarily with the occur- 
rence of selective outgrowth in the presence of the multiterminal type of nerve endings that are found in the musculature of these forms. That there is any such thing as myotypic specification or modulation of nerve by muscle becomes now an open question. The evidence for selective reinnervation in his own experiments along with our present findings suggests that the exclusion of such selectivity as an explanatory factor in earlier studies may have been overly hasty and that it may be well now to take another hard look at the whole question of selectivity in the growth and connexion of vertebrate peripheral nerve.

SUMMARY

1. Regeneration of nerve-muscle connexions was studied in the oculomotor system of the cichlid fish, Astronotus ocellatus. Complete section of the main nerve trunk of cranial nerve III either within the orbit or intracranially was followed by rapid full recovery of normal eye movements indicating coordinated activation of the four extrinsic oculomotor muscles.

2. Section of individual muscular branches of the nerve and the transplantation of these into foreign denervated oculomotor muscles in a variety of combinations was followed by recovery of abnormal muscle contractions that tended to be weaker than normal and timed according to the original muscle from which the nerve branch was taken. These and other results including tests of the competitive reinnervation of individual muscles point to preferential peripheral reinnervation rather than myotypic respecification.

3. The results suggest a need for reexamination of some of the earlier reports on muscle innervation, especially those dealing with myotypic specification, to see if selective peripheral innervation has in fact been eliminated.

\section{RÉSUMÉ}

Sélectivité de la régénération du nerf oculomoteur du poisson Astronotus ocellatus

1. La régénération des connexions neuro-musculaires a été étudiée dans le système oculomoteur du Astronotus ocellatus. La section complète du tronc nerveux principal du nerf cranial III, soit à l'intérieur de l'orbite soit à l'intérieur du crâne, est suivie de la reprise rapide et complète des mouvements de l'œil-ce qui indique une activité coordonnée des quatre muscles extrinsèques oculomoteurs.

2. Des sections individuelles de branches musculaires du nerf et leur transplantation dans des muscles oculomoteurs dénervés ont été effectuées suivant des combinaisons variées. Elles sont suivies par la reprise de contractions musculaires anormales qui tendent à etre plus faibles que normalement et dont le rhythme correspond au muscle dont provient la branche nerveuse. Ces résultats et d'autres relatifs à des tests de la réinnervation compétitive des muscles individ- 
uels tendent à montrer une réinnervation périphérique préférentielle plutôt qu'une respécification myotypique.

3. Ces résultats suggèrent qu'il est nécessaire de reconsidérer certains des travaux antérieurs sur l'innervation musculaire, en particulier ceux qui concernent la spécification myotypique, afin de décider si l'innervation périphérique sélective a réellement été éliminée de ces expériences.

\section{ACKNOWLEDGEMENT}

This investigation was supported by the National Institute of Mental Health, Grant MH-03372, and the F.P. Hixon Fund.

\section{REFERENCES}

Arora, H. L. \& SPerry, R. W. (1957a). Functional recovery following section and regeneration of motor ocular nerves. Ann. Biol. Rpt. C.I.T. p. 98-9.

ARORA, H. L. \& SPERRY, R. W. (1957b). Myotypic respecification of regenerated nerve-fibres in cichlid fishes. J. Embryol. exp. Morph. 5, 256-63.

ARORA, H. L. \& SPERRY, R. W. (1963). Color discrimination following optic nerve regeneration in the fish, Astronotus ocellatus. Devl. Biol. 7, 234-43.

Arora, H. L. \& Sperry, R. W. (1964). Selectivity in regeneration and reconnection of the oculomotor nerve in cichlid fishes. Anat. Rec. 148, 357.

Bender, M. B. \& Fulton, J. F. (1938). Functional recovery in ocular muscles of a chimpanzee after section of oculomotor nerve. J. Neurophysiol. 1, 144-51.

BernsteIN, J. J. \& GUTH, L. (1961). Nonselectivity in establishment of neuromuscular connections following nerve regeneration in the rat. Expl Neurol. 4, 262-75.

GuTH, L. (1961). Selectivity in the reestablishment of synapses in the superior cervical sympathetic ganglion in the cat. Expl Neurol. 4, 59-69.

GuTH, L. (1962). Neuromuscular function after regeneration of interrupted nerve fibers into partially denervated muscle. Expl Neurol. 6, 129-41.

GuTH, L. (1963). The problem of selectivity between nerve and end-organ following nerve regeneration. In: Proceedings of Symposium on the Effect of Use and Disuse on Neuromuscular Functions (Sept. 18-23, 1962). Prague: Czech. Acad. Sci.

MARK, R. F. (1965). Fin movement after regeneration of neuromuscular connections: An investigation of myotypic specificity. Expl Neurol. 12, 292-302.

SPERRY, R. W. (1946). Ontogenetic development and maintenance of compensatory eye movements in complete absence of the optic nerve. J. comp. Psychol. 39, 321-30.

SPERRY, R. W. (1947). Nature of functional recovery following regeneration of the oculomotor nerve in amphibians. Anat. Rec. 97, 293-316.

SPERRY, R. W. (1950). Myotypic specificity in teleost motorneurons. J.comp. Neurol.93,277-88.

SPERry, R. W. (1958). Physiological plasticity and brain circuit theory. In: H. F. Harlow and C. N. Woolsey (Eds.), Biological and Biochemical Bases of Behavior. Madison: Univ. Wisconsin Press. Pp. 401-24.

SperRy, R. W. (1965). Embryogenesis of behavioral nerve nets. In: R. L. DeHaan \& H. Ursprung (Eds.), Organogenesis. (In press).

Sperry, R. W. \& Deupree, Norma (1956). Functional recovery following alternations in nerve-muscle connexions of fishes. J. comp. Neurol. 106, 143-61.

WARTENBerg, R. (1946). Associated movements in the oculomotor and facial muscles. Archs Neurol. Psychiat., Chicago. 55, 439-88.

Weiss, P. A. (1928). Erregungspecifität und Erregungs-resonanz. Ergebn. Biol. 3, 1-151.

WeIss, P. A. (1931). Das Resonanzprinzip der Nerventätigkeit. Wien. klin. Wschr. 39, 1-17.

WEISS, P. A. (1936). Selectivity controlling the central peripheral relations in the nervous system. Biol. Rev. 11, 494-531. 
Weiss, P. A. (1937). Further experimental investigations on the phenomenon of homologous response in transplanted amphibian limbs. Nerve regeneration and the innervation of transplanted limbs. J. comp. Neurol. 66, 481-535.

Weiss, P. A. (1955). Nervous system (Neurogenesis). In: Analysis of Development, B. H. Willier, P. Weiss, V. Hamburger (Eds.), Philadelphia: Saunders, 346-401.

Weiss, P. A. \& HoAG, A. (1946). Competitive reinnervation of rat muscles by their own and foreign nerves. J. Neurophysiol. 9, 413-8.

Weiss, P. A. \& TAYLOR, A. C. (1944). Further experimental evidence against 'neurotropism' in nerve regeneration. J. exp. Zool. 95, 233-57,

(Manuscript received 2nd August 1965) 